\title{
On a Sophisma of Richard Kilvington and a Problem of Analysis
}

\author{
BERNARD D. KATZ
}

University of Toronto

In his discussion of one of Richard Kilvington's sophismata, Norman Kretzmann has drawn attention to an interesting puzzle on the nature of linguistic analysis. ${ }^{1}$ Richard Kilvington was a fourteenth-century English philosopher, one of the so-called "Oxford calculators," and his Sophismata is a series of perplexing sentences and accompanying discussions, designed to illuminate various issues in natural philosophy and epistemology. ${ }^{2}$ The sophisma that gives rise to Kretzmann's concern is the first, the peculiar sentence

(1) Socrates is whiter than Plato begins to be white. ${ }^{3}$

We are to understand the sentence as comparing the whiteness of two objects, of two swatches of cloth in a container of bleach, say. ${ }^{4}$ Kilvington contends that the sentence is true if, for example, the Socrates swatch is white and, at the same time, the Plato swatch begins to be white. In his account, an object begins to be white just in case it now is not white but immediately after now is white. Suppose, then, that Socrates is white and Plato begins to be white. According to Kilvington, since Socrates now is white and Plato is not, some time will have to elapse before Plato is as white

I am grateful to Jack Canfield, Avrum Fenson, Elmar Kremer, and Norman Kretzmann for helpful comments and suggestions.

1. Norman Kretzmann, "Socrates Is Whiter Than Plato Begins to be White," Noûs 11 (1977): 3-15.

2. Richard Kilvington, The Sophismata of Richard Kilvington, trans. Norman Kretzmann and Barbara Ensign Kretzmann (Cambridge: Cambridge University Press, 1990).

3. Kilvington, Sophismata, p. 2. The text of Sophisma 1 occurs as the appendix to Kretzmann, "Socrates Is Whiter," pp. 14-15.

4. In his exposition, Kretzmann suggests that one might "think of Socrates as a floodlight on at full power and Plato as a floodlight which is now off but connected to a rheostatic switch that someone has just taken hold of for the purpose of turning Plato on to full power" ("Socrates Is Whiter," p. 6). He remarks that while the names 'Socrates' and 'Plato' are often used in sophismata, as far as he knows they are never used with any suggestion of reference to actual historical figures; rather they are used in the manner of arbitrary constants (p. 13, n. 13). 
as Socrates now is; hence, Socrates now is whiter than Plato will immediately be. But in that case (1) is true. ${ }^{5}$

In his own Sophismata, Albert of Saxony, a fourteenth-century logician at the University of Paris, criticizes Kilvington's treatment of this sophisma, arguing in particular that (1) is both deviant and unintelligible. ${ }^{6}$ Albert's reasoning, as I understand it, runs as follows: it is a criterion of a successful analysis that one may interchange analysandum and analysans salva congruitate. Following Kilvington, we may analyze the sentence 'Plato begins to be white' as 'Plato now is not white and immediately after now he will be white'. But the result of replacing 'Plato begins to be white' with 'Plato now is not white and immediately after now he will be white' in (1) is the plainly incoherent sentence

(2) Socrates is whiter than Plato now is not white and immediately after now he will be white.

Since (2) is incoherent, and since (2) comes from (1) by replacing an analysandum with an analysans, it follows that if the analysis is sound, then (1) itself is incoherent.

Kretzmann contends that while the sophisma may give one pause, it nevertheless makes sense. He argues that Albert's argument must be fallacious on the grounds that by using similar procedures, we could make "Saxon hash" of comparison sentences that we know are unquestionably all right. Kretzmann invites us to consider, as an example, the sentence

(3) Socrates began to be white sooner than Plato began to be white.

Using Albert's recipe, Kretzmann says, we can obtain

(4) Socrates at $t_{1}$ was not white and immediately after $t_{1}$ he was white sooner than Plato at $t_{2}$ was not white and immediately after $t_{2}$ he was white,

which again is clearly incoherent. ${ }^{7}$ Since (3) is perfectly grammatical, there must be something wrong with Albert's argument (assuming, of course, that the analysis of 'begins to be white' is correct). Though Kretzmann concludes that Albert's demonstration is fallacious, he remarks that he is

5. Kilvington, Sophismata, p. 2.

6. Kretzmann, "Socrates Is Whiter," pp. 8-9.

7. It may be worth noting that (4) is not strictly parallel to (2). The analysis of 'Plato begins to be white' as 'Plato now is not white and immediately after now he will be white' uses the temporal indicator 'now', reflecting the fact that the analysandum is in the present tense. The incipit sentences in (3), however, are in the past tense. Accordingly, the temporal reference in (4) should be to indefinite times in the past: for example, 'There is a time $t$ such that $t$ is before now, Socrates at $t$ was not white, and immediately after $t$ he was white sooner than there is a time $t$ such that $t$ is before now, Plato at $t$ was not white, and immediately after $t$ he was white'. I do not see, however, that this affects the substance of Kretzmann's point. 
unsure exactly what the source of the fallacy is: "It is not difficult to raise a plausible ad hoc barrier against Albert's line of attack, but I would like to know the theoretical basis for such a barrier." 8

I think that Kretzmann is right in his claim that (1) makes sense and, hence, also in his contention that Albert's demonstration is fallacious. This, however, raises a perplexing question about linguistic analysis. Surely, if an analysis is correct, substituting analysans for analysandum cannot take us from sense to nonsense. But then, how can we reconcile the obvious incoherence of (2) with Kilvington's analysis of 'Plato begins to be white' and the assertion that (1) makes sense? I think that we can reconcile these ideas, and in what follows I shall try to show how. My account, if sound, explains in particular why Albert's argument is fallacious. I begin, however, by considering briefly another attempt at diagnosing Albert's mistake.

\section{I}

In a discussion of this problem, Calvin Normore tries to pinpoint the source of the fallacy in a mistaken assumption about analysis.

My proposal is that Albert is mistaken in thinking that the correct analysis of an expression has to preserve the grammatical category of the expression. This amounts, I think, to the claim that grammatical form mirrors logical form in natural language and is refuted by theories, like Russell's theory of descriptions, in which expressions of one grammatical category are analyzed as being of another or even, as with Russellian descriptions, of no grammatical category at all. ${ }^{9}$

Normore is correct in saying that a successful analysis may alter the grammatical category of the analysandum if by this he means that it may alter the grammatical form of the expression; for example, in Russell's theory of descriptions a sentence having the grammatical form of a subject-predicate sentence turns out to have the logical form of an existential generalization. But if this is what he means, it is hard to see how it is relevant to Albert's argument against the grammaticality of (1), for the argument assumes that (1) and (2) are alike in grammatical character, not in grammatical category; that is, it assumes that (1) is coherent if and only if (2) is, not that they have the same grammatical form. Someone might, of course, suppose that if a successful analysis may alter grammatical form, it may also alter grammaticality. This, however, would be a mistake. The whole point of an analysis is to preserve meaning; so, while the correct analysis of an expression may change the grammar of the expression, it cannot change its meaning. But

8. Kretzmann, "Socrates Is Whiter," p. 9.

9. Calvin Normore, "Ockham on Mental Language," in Historical Foundations of Cognitive Science, ed. J. C. Smith (Dordrecht, Neth.: Kluwer, 1990), p. 65. 
if two expressions have the same meaning, it makes no sense to suppose that one is coherent and the other is not. If, for example, (2) constitutes a correct analysis of (1), then it must be (at least) logically equivalent to (1), in which case it makes no sense to say that (1) is grammatical but (2) is not.

Accordingly, although I agree that the view that Normore attributes to Albert-namely, that a successful analysis must preserve the grammatical form of the analysandum-is mistaken, I do not see that it is relevant to Albert's argument. I think, however, that Normore's claim that Albert's demonstration assumes a mistaken conception of analysis is right; and while the mistake is not the one Normore attributes to him, it is one that Normore identifies.

Normore's discussion of this problem occurs in the context of an examination of William Ockham's account of mental language. According to Normore, it is a consequence of Ockham's account of mental language that "an analysis will be acceptable only if replacement of the analysandum by the analysans preserves grammaticality in mental language." 10 Normore goes on to point out that Ockham's criterion does not imply that "such replacement will preserve grammaticality in the spoken language." This, I think, does help us to see the fallacy in Albert's reasoning. If the notions of mental language and spoken language are taken-as Normore suggests-as that of logical form and grammatical form, respectively, then the point that emerges is that replacing a component of an expression with a correct analysis of that component does not necessarily preserve grammaticality. This, of course, is compatible with the claim, urged above, that a correct analysis of an expression must always preserve grammaticality, for replacing a component of an expression with a correct analysis of the component does not necessarily constitute a correct analysis of the expression.

Albert's argument assumes that an analysis is correct only if one may always substitute the analysans for the analysandum salva congruitate. In particular, the argument assumes that if some sentence $s_{1}$ occurs as a grammatical component of another sentence $s_{2}$, then if $s_{2}$ is coherent, so is the result of replacing $s_{1}$ with a sentence that is logically equivalent to $s_{1}$. This assumption, however, is surely false when logical form and surface grammatical form do not converge. For example, the sequence of words 'Abel is a sibling' constitutes a grammatical sentence of English; and that sequence occurs in the sentence 'Abel is a sibling of Cain'. But even though 'Abel is a sibling' is logically equivalent to 'Abel has a parent in common with someone else', the result of replacing the former with the latter in 'Abel is a sibling of Cain' is nonsensical. The problem is that while the sequence of words 'Abel is a sibling' can function as a sentence and though that sequence of words does occur in the sentence 'Abel is a sibling of Cain', it does not occur as a sentential component of 'Abel is a sibling of Cain'. As far as logical form is concerned, the phrase 'of Cain' does not create a sentential context, and 'Abel is 
a sibling of Cain' is not a compound sentence containing 'Abel is a sibling' as a component. So despite superficial appearance, the sentence 'Abel is a sibling' does not occur as a logical unit of 'Abel is a sibling of Cain'.

\section{II}

A sentential context (where that is understood as referring exclusively to a feature of the logical framework of a sentence) will permit the interchange of logically equivalent sentences within its scope salva congruitate. However, the replacement of an expression that occurs merely as a grammatical segment of some sentence with a logically equivalent expression may well fail to preserve the grammatical character of that sentence. This, I think, points to the fallacy in Albert's demonstration and provides a theoretical basis for blocking his attack.

Kretzmann's counterexample illustrates the fallacy quite nicely. Certainly, 'sooner than' in (3) is a grammatical conjunction joining the two clauses 'Socrates began to be white' and 'Plato began to be white'. But 'sooner than' is not a sentential connective, nor are 'Socrates began to be white' and 'Plato began to be white' sentential constituents of (3), at least not in the logical sense. We can take 'sooner than' in the same way that Frege understands 'before', that is, as a two-place predicate true of times. Accordingly, we would treat (3) as saying something like this: Socrates began to be white at sometime, Plato began to be white at sometime, and the former time was sooner than the latter. So construed, we would take (3) as having the following logical form:

There are times $t$ and $t^{\prime}$ such that Socrates began to be white at $t$, Plato began to be white at $t^{\prime}$, and $t$ was sooner than $t^{\prime}$.'

It turns out, as a consequence, that (3) is really an existentially quantified conjunction, with variables ranging over times. We see, moreover, that 'Socrates began to be white' and 'Plato began to be white' do not occur as sentential constituents of the logical form of (3); they occur merely as proper parts of the simple predicate expressions 'Socrates began to be white at $t$ ' and 'Plato began to be white at $t$ ', respectively. Replacing 'Socrates began to be white' in (3) with the sentence 'Socrates at $t_{1}$ was not white and immediately after $t_{1}$ he was white'-as the inference from (3) to (4) requires-is akin to replacing 'Abel is a sibling' in 'Abel is a sibling of Cain' with 'Abel has a parent in common with someone else': it is no wonder in either case that we end up with nonsense.

The inference from (1) to (2) is fallacious, I think, for much the same reason that the inference from (3) to (4) is: it confuses surface grammar with logical form. Consider the unexceptionable comparison sentence

(5) Socrates is whiter than Plato is white. 
The word 'than' in the phrase 'whiter than' is, of course, a grammatical conjunction. But considering the very limited range of sentences that may be substituted salva congruitate for 'Plato is white' in (5), we are not likely to take seriously the idea that 'than' functions as a sentential connective in (5) or, accordingly, that it creates a sentential context in (5). ${ }^{11}$ But in that case even though 'Plato is white' figures in the grammar of (5), it does not occur as a sentential constituent of the logical form of (5). What exactly does (5) say? Obviously, (5) compares Socrates and Plato, but it does so in terms of how white they are, that is, in terms of their respective degrees of whiteness. It says something like this: Socrates has a certain degree of whiteness, Plato has a certain degree of whiteness, and the former degree of whiteness is greater than the latter. We may, accordingly, represent (5) as having a logical form like the following:

(6) There are degrees of whiteness $x$ and $x^{\prime}$ such that Socrates is white to degree $x$ and no other, Plato is white to degree $x^{\prime}$ and no other, and $x$ is greater than $x^{\prime} .12$

Thus, (5) as well turns out to be an existentially quantified conjunction but with variables ranging over degrees of whiteness. Since (6) imputes a unique degree of whiteness to each of Socrates and Plato and the terms 'how white Socrates is' and 'how white Plato is' are definite descriptions that refer to degrees of whiteness, we can take (6) in the manner of 'How white Socrates is exceeds how white Plato is'. It is clear, however, on either representation that 'Plato is white' does not occur as a complete unit of the logical form of (5); it occurs merely as a proper part of a predicate term.

It is obvious that if the phrase 'Socrates is whiter than' does not create a sentential context in (5), it does not do so in (1) either. Consequently, the clause 'Plato begins to be white' does not occur as a sentential constituent of the logical form of (1). But then, even if the sentence 'Plato begins to be

11. The sentence 'Plato is white' is logically equivalent to 'There is someone who is white and is identical to Plato'; but the result of replacing the former with the latter in (5) is clearly nonsense. Since, as I remarked earlier, a sentential context will permit the interchange of logical equivalents salva congruitate, it follows that 'than' does not create a sentential context in (5).

12. The condition that Socrates is white to some degree of whiteness and no other and that Plato is white to some degree of whiteness and no other ensures that each has exactly one degree of whiteness. Of course, our present discussion highlights the fact that an object may be whiter at one time than another; so it would be more accurate to say that an object has a unique degree of whiteness at a given time. If we take the adjective 'white' as true of triples that consist of objects, times, and degrees of whiteness, we might express (6) in the manner of

$\mathrm{x} \quad \mathrm{x}^{\prime} \forall$ ( $\mathrm{y}$ [White (Socrates, now, $\left.\left.\mathrm{y}\right) \leftrightarrow \mathrm{y}=\mathrm{x}\right] \& \forall \mathrm{y}$ [White (Plato, now, y) $\left.\left.\leftrightarrow \mathrm{y}=\mathrm{x}^{\prime}\right] \& \mathrm{x}>\mathrm{x}^{\prime}\right)$.

In "Making Comparisons," Mind, 104 (1995), 369-92, I set out and try to defend a general account of the logical form of comparatives. 
white' may be correctly analyzed as 'Plato now is not white and immediately after now will be white', as both Richard Kilvington and Albert of Saxony urge, it does not follow that we may exchange the latter for the former in (1) salva congruitate. Since 'Plato begins to be white' is not a sentential constituent of the logical form of (1), replacing it with what may be a correct analysis of it, as it occurs in other contexts, need not preserve the grammaticality of (1).

According to Kretzmann, we are supposed to understand (1) as comparing Socrates's present whiteness and Plato's "incipient whiteness." 13 If so, we may take (1) as drawing a comparison between how white Socrates now is and how white Plato begins to be; that is, we may take (1) as saying, 'How white Socrates now is exceeds how white Plato begins to be'. Using Kilvington's analysis of 'begins to be white', we can, however, eliminate that phrase from (1), for given his analysis, how white Plato begins to be is identical with how white Plato will be immediately after now (if it is identical with anything). Hence, we may analyze (1) as saying something like this: Socrates now has a certain degree of whiteness, Plato now has no degree of whiteness but immediately after now will have a certain degree of whiteness, and the former degree of whiteness is greater than the latter. In other words, given Kilvington's analysis of 'begins to be white', (1) is equivalent to

(7) There are degrees of whiteness $x$ and $x^{\prime}$ such that Socrates is now white to degree $x$ and no other, there is no degree of whiteness such that Plato is now white to that degree but Plato immediately after now is white to degree $x^{\prime}$ and no other, and $x$ is greater than $x^{\prime} \cdot 14$

Unlike Albert's (2), (7) is perfectly coherent. ${ }^{15}$

We see, as a consequence, that we can reconcile the idea that (1) is coherent with the observation that replacing the embedded occurrence of

13. Kretzmann, "Socrates Is Whiter," p. 7.

14. Using the format sketched earlier, we may phrase (7) in the manner of

$\mathrm{x} \quad \mathrm{x}^{\prime}(\forall \mathrm{y}[$ White (Socrates, now, $\mathrm{y}) \leftrightarrow \mathrm{y}=\mathrm{x}] \& \sim \mathrm{y}$ (White (Plato, now, y) \& $\forall$ y[White (Plato, immediately after now, $\left.y) \leftrightarrow y=x^{\prime}\right] \& x>x^{\prime}$ ).

15. Though I think that Kilvington's interpretation of (1) is perfectly intelligible, it seems to me that it has a somewhat different meaning in contemporary idiom. We would be unlikely to interpret 'begins to be white', as it occurs in the likes of (1), in the manner Kilvington proposes, that is, as describing something whose color has changed so that it now has some degree of whiteness. Rather, we would take that phrase simply as describing something that has a minimal degree of whiteness. It is natural, I think, to take (1) as saying simply that Socrates is vastly more white, perhaps even limitlessly more white, than Plato; compared to Socrates, Plato just begins to be on the relevant scale. On this reading, 'begins to be' is used simply to mark a great contrast in degree of whiteness. A boastful parent who says, 'My child is smarter than your child begins to be' does not mean to be taken as saying that the intellect of the less intelligent child is in a state of flux; quite the contrary. 
'Plato begins to be white' with a correct analysis of that sentence generates nonsense. Our account shows not only that Albert's objection to the sophisma is ill founded but also where exactly his line of attack goes astray. The sequence of words 'Plato begins to be white' can occur as a simple sentence, and it can also occur as part of another sentence. But when a sequence of words that can function as a simple sentence occurs merely as a grammatical component in some sentence, it does not have the same meaning-in particular, the same logical grammar-as it does when it stands alone. Since 'Socrates is whiter than' does not create a sentential context in (1), 'Plato begins to be white' does not occur as a sentential constituent of (1). Therefore, there is no reason to expect that replacing 'Plato begins to be white' in (1) with a sentence that is equivalent to it, when it functions as a sentence, might not alter the grammaticality of (1). Thus, Albert's demonstration involves the replacement of something that occurs as a grammatical, but not as a logical, component of the sophisma; and for that reason the resulting analysis is neither correct nor grammatical. 